\title{
Manufacturing supply chain modelling and reengineering
}

\author{
KUMAR BHASKARAN and YING TAT LEUNG \\ IBM Corporation, Research Division, Thomas J. Watson Research Center, \\ P.O. Box 218, Yorktown Heights, NY 10598, USA \\ e-mail: [bha,ytl]@watson.ibm.com
}

\begin{abstract}
The first-wave of reengineering, during the first half of the nineties, focused on making organizational changes and used primarily information models of supply chains to integrate business processes. Quantitative models are expected to have a significant impact in the second-wave of reengineering through the deployment of performance and optimization models, economic analysis, and decision support systems. In this paper, we focus on the vital role that quantitative modelling techniques such as those founded in Operations Research and Industrial Engineering can play in reengineering supply chains. These quantitative models can extend the business process reengineering concepts to provide a concurrent reengineering framework for modelling the supply chain processes, identifying reengineering opportunities, evaluating design alternatives, guiding the selection of the best alternative, and deploying tools to implement the design. We illustrate such use by surveying current industrial practice and introducing real world examples based on our practical experience in solving supply chain and reengineering problems.
\end{abstract}

Keywords. Business process reengineering; supply chain management; quantitative models.

\section{Introduction}

The commercial potential of a global market as well as the significant advances in information and communication technologies is driving companies world-wide to reengineer their deployed assets and distributed capabilities to form manufacturing supply chains that offer significant business advantages. A manufacturing supply chain is an integrative approach to manaing the inter-related flows of products and information among suppliers, manufacturers, distributors, retailers, and customers. It consists of cooperative inter-linked processes that transcend production, distribution, and transportation functions and permit the coordination of strategies, tactical plans, and operations across these functions. Supply chains are a major departure from the traditional ways in which businesses have been organized, i.e., vertically integrated along functional lines with significant built-in inefficiencies in terms of time and cost to bring products to the market. 
Constituting manufacturing supply chains therefore requires major structural changes in the way companies are organized to produce and distribute goods and services. A widely adopted approach, with mixed success, in making these changes is business process reengineering (BPR). In BPR, like in manufacturing supply chains, the business process is viewed as a horizontal flow of activities. There is a wide range of opinion on what constitutes BPR. Hammer \& Champy (1993) define BPR as a breakaway from old rules, adopting a radical approach to changing business. Hammer and Champy's approach involves four basic stages in BPR, namely, mobilization of a team, diagnosis to identify weaknesses in existing design, redesign to create breakthroughs, and transition to roll out and institutionalize the results. Harrington (1992) on the other extreme views BPR as an incremental process improvement approach. Aikins (1993) regards BPR as a redesign process that leverages the potential of information technology.

Manufacturing supply chains and BPR emerged as independent concepts in the mideighties and early nineties respectively and as such are well documented. In this paper, we focus on the vital role that quantitative modelling techniques such as those founded in Operations Research (OR) and Industrial Engineering (IE) can play in reengineering supply chains. These quantitative models can extend the BPR concepts to provide a framework for modelling the supply chain processes, identifying reengineering opportunities, evaluating design alternatives, guiding the selection of the best alternative, and deploying tools to implement the design. We will illustrate this framework by introducing real world examples based on our practical experience in solving supply chain and reengineering problems.

The paper is organized in five sections. Following the introduction, the interest in supply chains and the motivation for modelling supply chains is reviewed in $\S 2$. Section 3 looks at the role and impact of quantitative modelling in reengineering. Practical examples illustrating the use of quantitative models in reengineering are presented in $\S 4$. Finally, $\S 5$ offers some conclusions.

\section{Why model supply chains?}

Consider for example a large manufacturing company that caters to a global market and has assets deployed world-wide. A scenario analysis based on a typical consolidated financial summary is shown in figure 1 to illustrate the performance expectations that motivate supply chain management. Supply chains impact the five basic variables that are commonly used in measuring business performance, namely, sales, cost of goods sold, expenses, inventory, and accounts receivable.

As is clear from figure 1, the profitability and efficiency of the enterprise can be improved dramatically if gains can be realized along multiple performance dimensions (modelled by progressively changing the basic variables in the scenario analysis). Supply chains by virtue of their comprehensive enterprise-level focus have the potential to realize such concurrent performance. Therefore, from a business standpoint supply chains merit attention and this observation is also reinforced by the rapidly growing supply chain software market (currently estimated to be $\$ 8$ billion in the US).

Another basic reason for the growing interest in supply chains is because companies such as Honda and Wal-Mart have very successfully demonstrated that competing on 


\begin{tabular}{|lccccc|}
\hline Impact Variables & $\mathbf{1}$ & $\mathbf{2}$ & $\mathbf{3}$ & $\mathbf{4}$ & $\mathbf{5}$ \\
Sales & 1.00 & 1.00 & 1.02 & 1.02 & 1.02 \\
Cost of Goods Sold & 1.00 & 1.00 & 1.00 & 1.00 & 0.99 \\
Expenses & 1.00 & 1.00 & 1.00 & 1.00 & 0.99 \\
Inventory & 1.00 & 0.90 & 0.90 & 0.90 & 0.90 \\
Accounts Receivable & 1.00 & 1.00 & 1.00 & 0.95 & 0.95 \\
Profitability & & & & & \\
Return on Equity & $18.36 \%$ & $18.36 \%$ & $24.77 \%$ & $24.77 \%$ & $27.64 \%$ \\
Return on Net Assets & $15.61 \%$ & $15.81 \%$ & $18.81 \%$ & $19.28 \%$ & $20.65 \%$ \\
Return on Sales & $10.55 \%$ & $10.55 \%$ & $12.31 \%$ & $12.31 \%$ & $13.18 \%$ \\
Net Profit Margin & $5.72 \%$ & $5.72 \%$ & $7.57 \%$ & $7.57 \%$ & $8.45 \%$ \\
Efficiency & & & & & \\
Inventory Turns & 6.57 & 7.31 & 7.31 & 7.31 & 7.23 \\
A/R turns & 3.07 & 3.07 & 3.14 & 3.30 & 3.30 \\
Total Asset Turnover & 0.90 & 0.90 & 0.92 & 0.93 & 0.93 \\
Net Asset Turnover & 1.48 & 1.50 & 1.53 & 1.57 & 1.57 \\
\hline
\end{tabular}

Notes:

- Scenario 1 represents the base case or the current performance,

- Scenario 2 represents a $10 \%$ reduction in inventory costs from the base case,

- Scenario 3 adds a $2 \%$ gain in sales revenues over the base case to scenario 2 and so on.

- The profitability and efficiency measures are based on standard financial management definitions.

Figure 1. Scenario analysis illustrating potential gains from supply chains.

capabilities to produce and deliver is equally if not more important than the products themselves. Consequently, in companies that are market leaders, the building blocks of corporate strategy are not products and markets but business processes that constitute supply chains (Stalk et al 1992). At the same time reengineering business processes to form supply chains, to realize the performance projected in figure 1, introduces formidable challenges.

The nonlinear impact of the individual performance dimensions on overall profitability and efficiency is readily apparent from the analysis presented in figure 1. In fact, this nonlinearity is inherent in the complex and conflicting trade-off that characterizes the operations of supply chains. The large-scale physical production and distribution network for material flow, the uncertainties associated with the external customer and supplier interfaces, and the myriad cross-functional and nonlinear dynamics associated with internal information flows, are some of the factors that contribute to the supply chain complexity. Lee \& Billington (1992) have studied supply chains in electronics, computer, and automobile industries and identified a number of pitfalls that companies face due to the complexity of supply chains. Some of these include the lack of supply chain performance metrics, simplistic inventory policies, ignoring the impact of uncertainties, poor coordination among divisions constituting the supply chain, and inadequate consideration of inventory and response time factors in economic analysis. They note the need to develop an understanding of the supply chain complexities to avoid these pitfalls.

Modelling is fundamental to understanding supply chain complexities and putting the insights to practical use in supporting and guiding business process reengineering. Cypress (1994) has noted that the first-wave of reengineering (during the first half of the nineties) focused on making organizational changes and used primarily information models of supply 
chains to integrate business processes. In this paper we are interested in the quantitative models of supply chains which are likely to have a significant impact in the second-wave of reengineering through the deployment of performance and optimization models, economic analysis, and decision support systems (Slats et al 1995). From here on modelling refers to quantitative modelling.

One of the earliest efforts of modelling a supply chain can be traced to Forrester (1958) who developed a simulation model of a production-distribution system to study its timedependent dynamic behaviour. Another early work by Hanssmann (1959) described an analytical model to determine optimal inventory levels in a manufacturing system composed of material procurement, production, and distribution elements. Cohen \& Lee (1988) were among the first to propose an analytical modelling framework to evaluate the performance of supply chains spanning functions from raw material procurement to finished goods delivery to customers. They have applied this framework to supply chains of automobile spare parts and personal computers (Cohen \& Lee 1990). Pyke \& Cohen (1990) developed a generalized Markov-chain model of a multi-product, three-echelon, production-distribution network and studied its performance.

A recent review of OR models in supply chains (Slats et al 1995) notes that most of the quantitative models that are reported in the literature are based on optimization and simulation. They observe that utilization of OR techniques and models to analyse the performance of the overall supply chain remain uncommon. The authors conclude that realistic OR models can make considerable contribution in diagnosing and redesigning business processes and facilitate the integration of supply chains. We concur with this observation based on our experience of using OR/IE models in reengineering supply chains.

One such model was for a large electrical component manufacturer (with an annual revenue of $\$ 700 \mathrm{M}$ ) who operated 10 final assembly plants throughout the US. Some key components were manufactured in-house in two plants in North America. Other raw materials were purchased. The 3000 or so active products were then distributed through a two-echelon warehouse system, shared by several distribution channels (with each channel focusing on a particular market segment). There were also products imported from overseas plants owned by the company. The lower echelon alone had five distribution centres serving the US market, with a small amount of export. This physical supply chain was managed by traditional business functions, such as forecasting, inventory management, production planning, transportation management etc., using a commercial supply chain management system augmented by in-house developed software. This scenario is fairly representative of discrete product manufacturers except for speciality suppliers. The performance model for this supply chain is described in $\S 4.1$.

\section{Quantitative modelling and reengineering}

BPR in a broad sense has come to signify the following:

- development of a shared understanding of the business processes,

- streamlining and integrating business functions both internal and external to the organization, and

- re-architecting enterprise-wide information systems, 
to manage and support planning, sourcing, making, and delivering activities that constitute a supply chain. In practice, companies have taken different tracks to reengineering supply chains that will offer high value at low cost. Some companies have concentrated on making process improvements while others have focused on upgrading and installing information systems. The results on the reengineering activities have been mixed. Gartner Group estimates that nearly $70 \%$ of typical BPR efforts fail to achieve the projected results. Although BPR efforts hinge on several factors for success, one vital factor is the availability of tools and an approach that allows BPR practitioners to effectively communicate among themselves as well as with IT professionals who are charged with implementing BPR related systems work. We believe that quantitative models and tools can be very effective in this context.

Despite the high visibility and cost of BPR efforts there is a lack of tools to support the reengineering activities (Childe et al 1994). A recent survey of the BPR tool market reveals that there are slightly over 50 or so programs widely ranging in price and functionality from $\$ 600$ for flowcharting software to $\$ 15 \mathrm{~K}$ for simulation modelling packages (Barrett 1996; Rovira 1996). These commercially available tools can be grouped into three categories.

(1) Information System departments in organizations have been traditionally using system development tools in BPR. These tools are capable of documenting processes qualitatively in terms of structured functional and input/output diagrams. The oldest and most widely used tool in this category is based on the IDEF (Integrated Definition for Function modelling) methodology that was developed by the US Air Force in the seventies for its integrated computer-aided manufacturing program [URL 1] ${ }^{*}$. Extensions to the IDEF methodology have been developed for enterprise modelling (Malhotra \& Jayaraman 1992). An example of commercial implementation of the IDEF methodology is WizdomWorks [URL 2].

(2) Groupware and computer-aided software engineering (CASE) vendors are incorporating graphical engines for business process modelling. The groupware tools have the ability to check consistencies in the process and workflow descriptions while the CASE tools provide an object-oriented representation of the business rules and even automatically generate codes for some software implementations. Although these tools are clearly an advancement over IDEF which is based on structured analysis and design they are only capable of qualitatively capturing processes. A list of workflow-based tools for BPR can be seen in [URL 3]. An example of workflow based tool is Business Process Modeler [URL 4] and an example of CASE based tool is ERwin/ERX for Teamwork [URL 5].

(3) At the high-end of BPR tools are discrete event simulation packages that provide tailored BPR modelling capability. These tools go well beyond describing the process and provide a means to quantitatively model supply chains and evaluate performance (Connors et al 1995). These tools include BPMAT [URL 6] developed by IBM, ARENA [URL 7] by Systems Modeling Corporation, and Extend + BPR [URL 8] by Imagine That Inc. The use of Extend + BPR is illustrated through the well-known reengineering example of IBM Credit, as described by Hammer \& Champy (1993)

\footnotetext{
${ }^{*}$ World-wide web reference, listed at the end.
} 
and Hansen (1994). Other general purpose simulation packages have also advertised BPR modelling capabilities.

A general list of BPR tools can be seen in [URL 9]. BPR tools with qualitative process modelling capabilities are inadequate in reengineering supply chains. The process descriptions such as those generated by IDEF are static functional snapshots and are very limited in articulating the existing process. Besides, these tools completely fail to capture the process dynamics and thereby ignore vast amounts of process knowledge. On the other hand, BPR tools with quantitative modelling capabilities can more precisely model processes and provide an effective means for visualizing, benchmarking, and articulating the BPR results. The role of quantitative modelling can best be appreciated when viewed in the context of the BPR approach.

Figure 2 shows the classical BPR approach (Hammer \& Champy 1993). The BPR approach has four basic stages: mobilization to form a reengineering team and generate a process map, diagnosis to develop an AS-IS understanding of the processes and identify areas for improvement, redesign to generate process breakthroughs and identify best design from several alternatives, and transition to pilot the TO-BE implementation and eventually roll out the results. These four steps are typically executed in sequence although there are significant iterative dependencies in the diagnosis and redesign stages. One reason for the sequential execution of the diagnosis and redesign stages is that most of the existing BPR tools that can qualitatively document processes do not support concurrency in these BPR stages.

In our view quantitative modelling can have an impact in the diagnosis, redesign, and transition stages of BPR. Further, quantitative modelling can introduce concurrency in the diagnosis and redesign stages as shown in the so-called "concurrent reengineering" approach in figure 3. As indicated at the outset, quantitative modelling can serve as a compelling and useful framework in documenting the supply chain processes, identifying reengineering opportunities, evaluating design alternatives, guiding the selection of the best alternative, and deploying tools to implement the design.

We have encountered in practice many common perceptions among management and staff within a company that have impeded the use of quantitative models. One such perception is that reengineering is a business problem and that quantitative models are not really applicable. Business problems are often founded on complex trade-offs. Quantitative models are particularly suited in identifying the factors that affect the trade-off, ascertaining the assumptions, and objectively framing the issues. Another common perception and an impediment to the use of quantitative models is that they are difficult to build and comprehend and are not process-oriented. With advances in quantitative modelling techniques (heuristics, simulation, and optimization), the availability of a number of rapid modelling tools, and easy access to powerful computing platforms it is possible to build large scale models quickly and animate/visualize them for easier comprehension. This is reinforced by examples in $\S 4$.

\section{Use cases of quantitative models in reengineering}

In this section we illustrate the use of quantitative models in the diagnosis, redesign, and transition stages of reengineering as well as the concurrent reengineering framework 


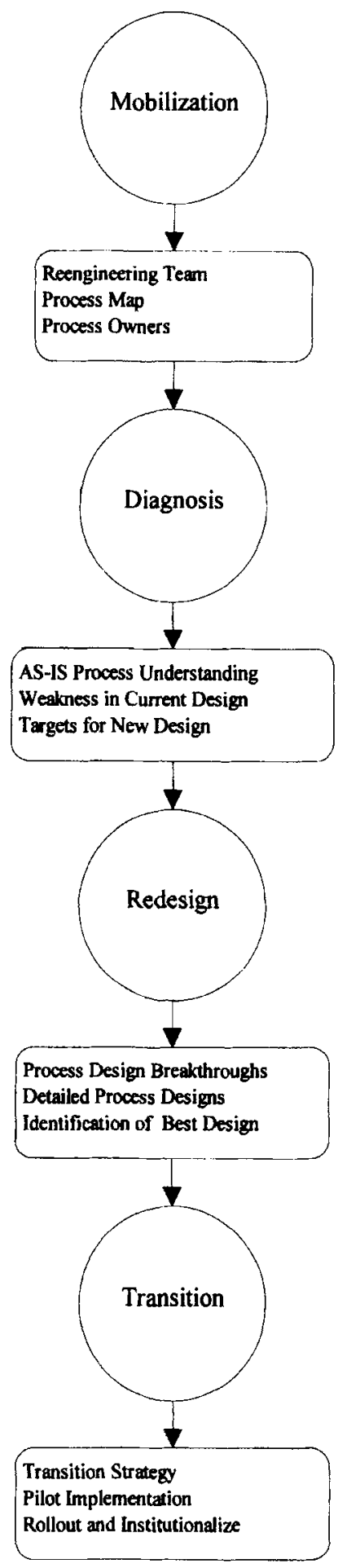

Figure 2. Sketch of classical BPR approach. 


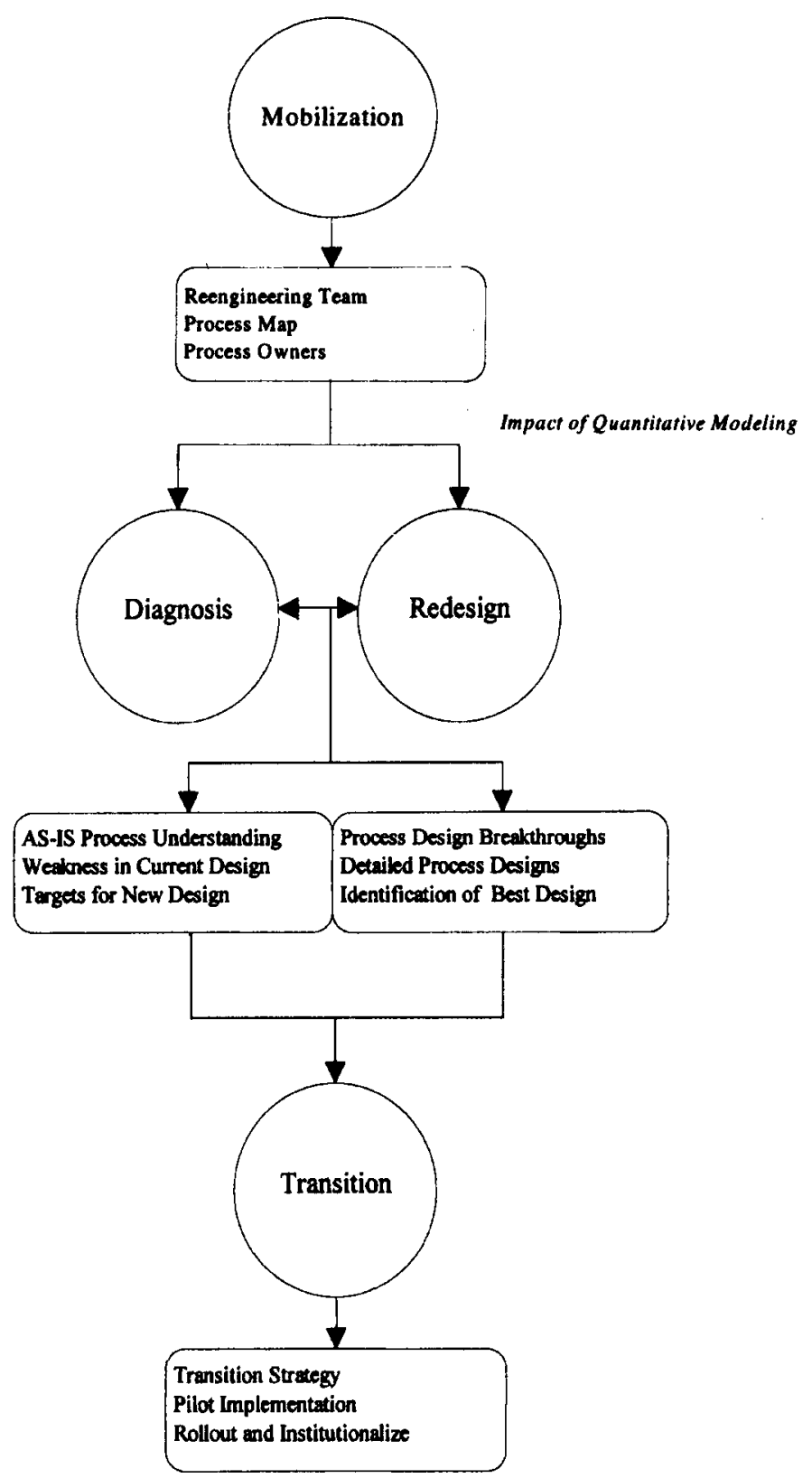

Figure 3. Sketch of concurrent reengineering approach. 
identified above, through some use cases. Section 4.1 samples the current state of industrial practice in this area, while $\S \S 4.2$ to 4.4 detail some of our practical experience in applying quantitative models.

\subsection{Overview of state of industrial practice}

Supply chains are usually complex, and it may not be obvious from the symptoms where to begin in terms of rethinking and redesigning the operations. Cypress (1994) observed that many reengineering projects are not successful because of the chosen scope of the project itself. If one had unlimited resources, the ideal approach would be to start from a blank sheet and design the business from scratch (Hammer \& Champy 1993). More commonly, reengineering projects have to be carried out with limited resources of budget and time. It is also very likely that reengineering efforts are initiated when business is not performing satisfactorily, placing severe constraints on the resources available for reengineering. It is therefore prudent to diagnose the supply chain quickly and accurately, so that resources can be targeted to areas that will yield the most improvement in overall performance.

An early example of using quantitative tools for diagnosing production-distribution systems is described in Hax et al (1980). In this study, the production and distribution planning, sales forecasting, and inventory management systems of a consumer package goods manufacturer were analyzed. First, a general data analysis was performed to describe the supply chain (such as what fraction of sales is generated where, and what products are contributing to what fraction of sales). An analysis of variance and exploratory data analysis were performed to analyse the forecast errors. The results give a direction of what forecasting strategy would be most beneficial (in this case a product-oriented approach, as opposed to a geography oriented one was picked). A simple, aggregate inventory model was built to examine the potential savings from reduced inventory levels. This model showed that safety stock was the largest component of inventory and identified the factors quantitatively.

A more recent example of model-based diagnosis is the study for the electrical component supply chain as described in $\S 4.2$. A high level quantitative model was developed to investigate the dynamic behavior of the supply chain (Bhaskaran \& Leung 1996). This performance model was composed of integrated analytical and simulation model components. A set of representative products were analysed and the goal was to determine high impact opportunities for an overall supply chain performance improvement. Through a series of what-if analyses, improvement opportunities were identified and ranked according to their impact. An important conclusion of this diagnosis was that improving the forecast error will not result in the kind of improvement management expected, contrary to popular belief within the company. Since the model covered all the key components of the supply chain, we found it useful as a documentation for the (then) current system, as well as a tool for redesign. This model is described in more detail in $\S 4.2$.

Redesigning a supply chain involves either one or both of the following: redesigning the business processes that constitute the management and operation of the supply chain and redesigning the physical production-distribution network that executes the material flow in the supply chain. Performing the latter often implies the execution of the former. For the purpose of this paper, by business process we mean a logical view of the process 
and distinguish it from the underlying physical production-distribution network. In usual reengineering terminology, a business process subsumes both the logical and physical views.

A key business process for a manufacturer is order fulfillment. This process defines how a company fills customer orders, starting from the receipt of a customer order and ending with the physical arrival of the ordered products at the customer specified destination. Depending on whether it is an assemble-to-order or assemble-in-advance situation, the order fulfillment process can include the actual final assembly of products. An example of using quantitative models to redesign an order fulfillment process is described in Feigin et al (1996). In fact, in this study, a simulation model of the supply chain of the IBM PC Company in Europe was developed to redesign the overall order fulfillment from assemble-inadvance to a combination of assemble-to-order and assemble-in-advance. New inventory planning policies and ways of allocating constrained components were introduced. The simulation model was used to quantify the benefits of these new processes and identify conditions under which they will be most beneficial.

In a similar spirit, simulation models developed with BPMAT, were used in a number of reengineering projects in IBM and others [URL 6]. For example, it was used in investigating opportunities for cycle time and cost reduction of a purchasing process. Various staffing and outsourcing alternatives were modelled during the process redesign stage. In the automobile industry, BPMAT models were developed in reengineering a wiringharness predesign process and an engineering change implementation process. A major goal of both these efforts was to reduce the cycle time involved.

On the supply side, a key process is production planning and scheduling. Fisher $e$ t al (1994) describe how a fashion-ski-apparel supplier reengineered its supply chain to cope with a changing business environment marked by uncertainty in demand. The company shortened its order processing times, changed the way it purchased raw materials, persuaded their customers to place orders sooner, and adopted a new forecasting and production scheduling approach. In particular, a quantitative model was developed for the purpose of creating a production schedule that minimized the risk of making a non-popular product. The model could also be used to analyse parametric changes to the physical supply chain, such as production capacity. The model was used to guide the continual refinements to the supply chain and product redesign process. It illustrates the concept of "concurrent reengineering" where diagnosis and redesign are done iteratively.

In Feigin et al (1996), the authors mention a new production planning process that takes into account constrained availability of components. Instead of performing a traditional MRP type calculation driven by finished goods requirement forecast, the production plan was formulated based on the most desirable allocation of the constrained materials (e.g. for maximizing revenue, fair allocation, product priority). An optimization model was developed to support this decision (Dietrich et al 1995).

In design/redesign of physical production-distribution network, the use of quantitative models are better established and a number of commercial model-based tools are available. An early practical work in this area is that of Geoffrion \& Graves (1974) (see also Geoffrion 1976). In this study, the problem of selecting sites for distribution centres, their sizes and customer zones, and the transportation flow patterns is modelled by a mixed integer mathematical program. The basic mathematical programming model was used by Hunt-Wesson 
Foods who were interested in conducting a systematic study of the entire distribution system to investigate opportunities for improvement and to resolve expansion and relocation issues. On the basis of the model recommendations, some existing distribution centres were relocated and new distribution centres were opened, while realizing significant annual cost savings. Recently, Pooley (1994) extended the basic model to include production facilities in a study for Ault Foods in Canada. Decisions related to production, such as what products must be produced in which plant and what plant should supply which distribution centre, were considered simultaneously with distribution decisions.

Similar in spirit, but larger in scale, to the Ault work is the global reengineering project carried out by Digital Equipment Corporation to restructure its supply chain on a worldwide basis (Arntzen et al 1995). Changes in the business environment such as rapid advancement of small computer and communication network technology led Digital "to reinvent itself" in order to survive in the new environment. It changed its conventional strategy of high vertical integration and focused on several core technologies. For example, it stopped producing power supplies and cables but retained semiconductors, modules, and systems. At the same time, the overall level of business decreased and the demand pattern had changed from moderate numbers of complex orders for large systems to large numbers of PCs and workstations. It was clear that Digital's supply chain needed to be redesigned. A large scale quantitative model was developed to aid this process. The model considered component supply (which vendors from where), production (which plants making what), and distribution (what customers to serve from where). It minimized a weighted combination of total costs and cycle times. A distinctive feature of this model is the consideration of global aspects of the supply chain, such as duties, taxes, trade and local content requirements. Besides redesigning the supply chain for existing products, the model was also used to configure supply chains for new products. The model was formulated as a mixed integer linear program.

A model of a similar flavor was developed at General Motors (GM) earlier, originally implemented in 1974 (Breitman \& Lucas 1987). The original intention of the model was to help determine the best strategies for placing facilities to support new products in new markets but was quickly expanded to include decisions such as those faced by Digital. The model was solved by (then) commercial mixed integer programming packages such as MPSX or SCICONIC (Sharda 1995), and was embedded in a decision-support system with business-oriented user interface.

At a more detailed level, the Delco division of GM performed a redesign of its distribution network by investigating its shipping strategy (Blumenfeld et al 1987). The goal was to reduce the inventory and transportation costs of Delco parts supplied to GM assembly plants. Alternatives included shipping parts from Delco plants directly to GM assembly plants, through a Delco warehouse, a combination of the two, or delivering to several GM plants with one truck load. A quantitative model was developed not only to identify the optimal strategy, which can serve as a benchmark for practical but simpler strategies, but also provide an objective means of analyzing the trade-off between transportation and inventory costs. The optimization model was solved by mathematical decomposition of the distribution network into individual links (Blumenfeld et al 1985).

In recent years, there have been a number of commercial software packages developed for optimizing the physical distribution network, solving problems similar to those 
considered by Geoffrion \& Graves (1974), and Pooley (1994) as mentioned before. These include PHYDIAS by Bender Management Consultants, Logistics Toolkit by CAPS Logistics [URL 10], and Locate 3+ by Cleveland Consulting. Most of these packages are based on solving a large scale mixed integer or linear mathematical program. A comprehensive survey of commercial tools in this area can be found in Leung (1995) and Ballou $\&$ Masters (1993). Although not designed for business process reengineering per se, they are very useful in reengineering physical supply chain networks. In addition, general purpose operations research/optimization toolboxes or packages can and have been used to solve distribution network design problems. Gangoli \& Jenkins (1988) report using SAS [URL 11] to improve the distribution network of Warner-Lambert as part of its strategic planning process.

Sometimes it is not necessary to use advanced optimization models for distribution network design. Mercer \& Tao (1996) used a relatively simple dynamic model to study alternative distribution policies of a food manufacturer supplying Tesco, a major grocery retailer in the UK. The model helped in deciding how products would be transshipped between the manufacturer's finished goods warehouses to satisfy Tesco's needs.

In the last several years, a notable development related to reengineering supply chains has been the concept of product design for supply chain management (Lee 1993). It is also known as design for logistics (Mather 1992). Similar to the well-known concept of design for manufacture, design for logistics is concerned with product design that allows effective delivery of products to customers. In particular, a key approach is delayed product differentiation in which the differentiation features within a product family are manufactured into the products as late as possible. For this purpose, an existing product may have to be redesigned or the design of a new product may result in higher material/manufacturing cost. In addition, semi-finished products carried in intermediate stockpiles may now bear a higher per unit value. It is important to analyze whether the resultant savings in supply chain costs (such as reduced finished goods inventory) and other benefits (such as increased flexibility leading to better customer service) can offset the incremental cost. Quantitative models are useful to this end. Lee (1996) presented two inventory performance models to support product design for delayed differentiation, and their real application cases (see also Lee \& Billington 1995).

One area that we do not see much reported in the technical literature is the use of quantitative models in the transition phase of a reengineering project. After a new process has been finalized, a roll-out is required to phase-in the new process. A key factor for the success of the new process is the training of staff who either manage or operate the process. Because the nature of reengineering stipulates that the new process may be totally new to the organization, management by experience alone is often not adequate. Here quantitative models of the process developed during the design phase can be valuable in familiarizing the staff with the process and providing management insight on the process dynamics. The latter cannot be gained from static models such as process charts or IDEF diagrams. Simulation models with graphical user interfaces are highly preferable.

Another important aspect of transition is the development or reconfiguration of information systems (transaction processing and decision support) to support the new process. Quantitative models developed during design are now useful as a building block for decision support systems or as a technology enabler of the new process (see $\$ 4.3$ ). Once 
the model is embedded in a decision support system, it can be used routinely for continual improvement of the process. Furthermore, quantitative models are very valuable in tuning operational or tactical planning systems. Typically, an operational system such as inventory/distribution requirements planning has many user specified parameters. While the parameters together make the system very flexible, it is often not obvious how they should be set to meet the business objectives. A quantitative model that captures the dynamics of the system (e.g. the one mentioned in $\$ 4.2$ ) is a tool to help optimize the parameter values.

\subsection{A supply chain performance model}

Management of supply chains that are engaged in the production and distribution of goods require a number of key management functions such as demand forecasting, inventory planning and control, production planning, manufacturing, and distribution. Ideally, these management functions work in cooperation to transform raw materials to finished goods and deploy them appropriately to meet the needs of the market. The presence of a large product portfolio, diverse markets, and uncertainties associated with the supply and demand processes are some of the prominent factors that contribute to the complexity of the individual management functions as well as their coordination in the overall management of a supply chain. Obviously, such complexity tends to make the decision making process difficult and challenging at the strategic and tactical levels of supply chain management.

Managing this complexity requires the visibility of how local decisions, within each management function, affect the overall performance and the competitive advantage of the supply chain. Supply Chain performance models provide insight on the impact of local decisions on global performance by exercising an aggregate quantitative dynamic model of the supply chain with various decision scenarios. We describe such a quantitative supply chain performance model. The development of the model was part of a larger effort in improving the profitability and customer service of the business through better strategic and tactical decision making. The model development included: Interviewing decision makers responsible for strategic and tactical decisions, gathering information on how the business operates, understanding the management requirements, and then building and validating the quantitative model.

The supply chain that was modelled is shown in figure 4. It is a scaled representation of the real supply chain and consists of the following physical elements: Ten representative products, three critical components (i.e., raw materials for final assembly) that are required for the production, a factory comprising two machine groups where the products are produced, a source warehouse that accepts the factory output, and a distribution system comprising ten field warehouses located all over the United States to cater to the national market. The supply chain comprising the aforementioned elements is managed collectively by the following essential management functions: Demand forecasting, inventory planning and control, production planning, manufacturing, and distribution.

The scaling of the actual system, to derive the supply chain shown in figure 4 , was necessary to define a manageable scope for the quantitative modelling exercise. It was done in cooperation with the management personnel of the supply chain to ensure that the scaled supply chain was in fact a representative cross-section of the overall supply chain. 


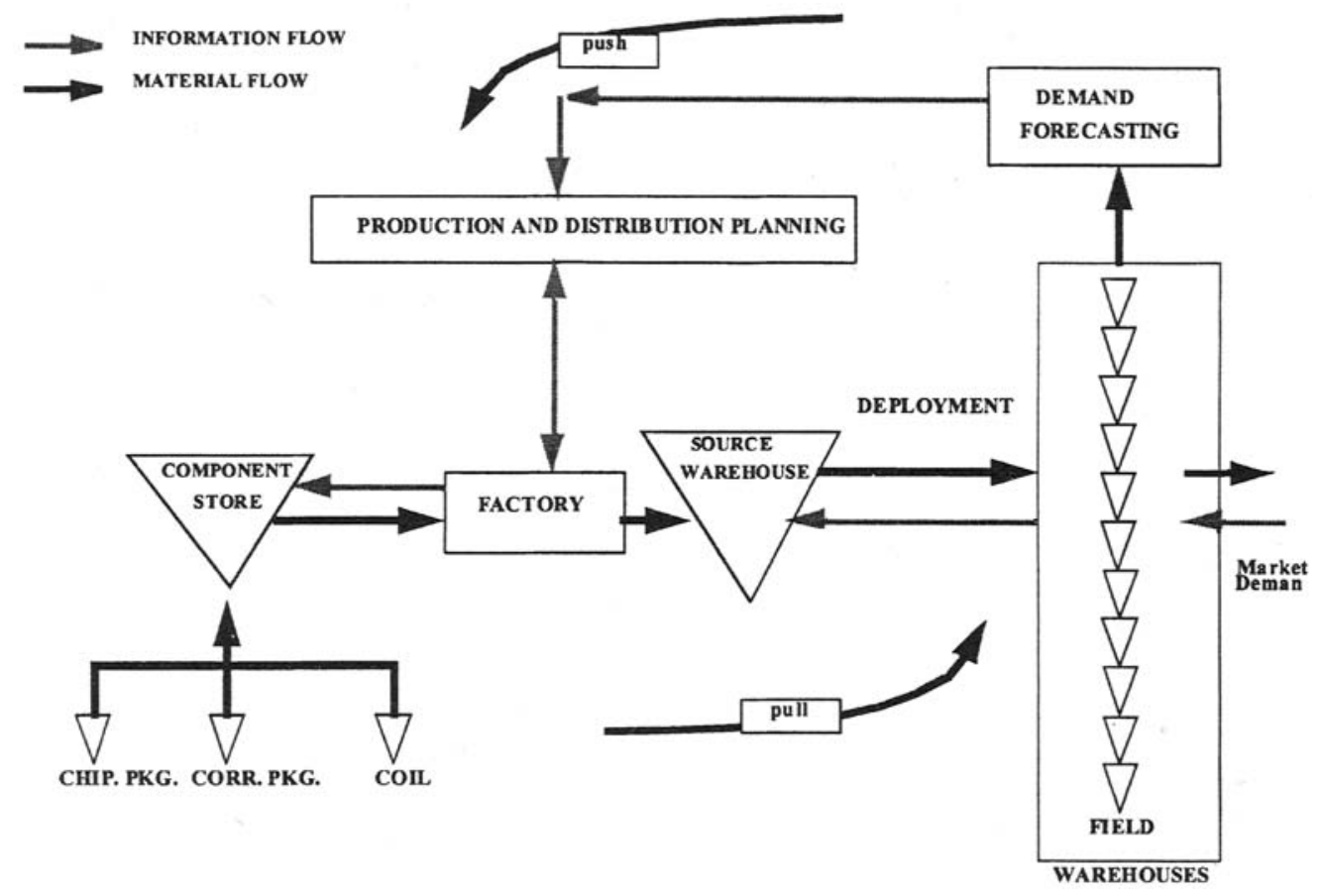

Figure 4. Schematic of supply chain information and material flows.

A detailed study of the overall operations was also conducted to understand the individual management functions and how they collectively worked within the supply chain in the real world.

Operationally, the supply chain can be classified as a make-to-stock business that is forecast driven. Specifically, no customer requests for products are directly entertained at the factory. As a consequence the supply chain can be viewed as a large scale push-pull system. The pull and push parts are referred to as the commercial and the manufacturing processes respectively. The commercial process is engaged in "selling" products to customers from the inventory that it previously "bought" from manufacturing. The quantity it "buys" at any point in time is governed by the forecast for product demand as well as its policies with respect to hedging against demand and stock replenishment uncertainties. On the other hand, the manufacturing process strives to make-to-stock based on the anticipated needs of the commercial organization. The push and the pull operations are phased apart by the manufacturing lead time, which is the time in advance that manufacturing plans to meet the future needs of the commercial process.

The development of the performance model involved the following steps.

(1) Defining the supply chain: This includes the structural constraints of the supply chain model, i.e., what the elements of the supply chain (physical elements such as the source warehouse and the management functions such as production planning) are, and how they operate as part of the supply chain.

(2) Specifying the model input: The model input includes the management variables and other data requirements. Management variables are parameters of the performance 
model and constitute an independent set of variables (that are different from other internal variables of the model). They are chosen based on the study of the real supply chain and in consultation with management personnel who are the end-users of the performance model. Some of the management variables include the forecast uncertainty for the demand forecasting function, planning frequency and time fence for the production planning function, lead time and delivery reliability for the component supply, run quantities and standard efficiencies for the factory, transit lead times for the distribution, and order quantities and service levels for the inventory planning function.

(3) Specifying the model output: This involves the specification of the performance measures that will be used to measure the performance of the supply chain, upon execution of the model. The supply chain performance is measured using pre-defined performance measures that are categorized as inventory-based and time-based. Inventorybased measures include on-hand inventory throughout the supply chain, inventory turn, and fill rates. Time-based measures include the customer order lead time, the manufacturing lead time and the overall system response time.

(4) Characterizing the elements of the supply chain: Mathematical models of the management functions in the supply chain (shown in figure 4) such as demand forecasting, production planning, and inventory planning, and the physical elements such as the factory, the source warehouse, and the field warehouses are developed. These models are sufficiently detailed to capture the impact of the management variables (item 2) on the performance measures (item 3 ).

(5) Developing the quantitative model: The individual mathematical representations of the elements in the supply chain are unified in a mathematical framework taking into account the various constraints. Such a quantitative characterization of the supply chain is referred to as the performance model.

It may be noted that the two flows that essentially integrate the supply chain are the material and information flows. The dynamics of these flows are shaped by the external factors such as the customer demand as well as the local decisions made by each management function. The two basic attributes of the dynamics are quantity and time. Recall that the performance measures for the model are also aptly categorized as inventory-based (i.e. quantity-based) and time-based. Any integrating mechanism must therefore feature these two basic attributes. Additionally such a mechanism must be consistent with the models of the individual elements of the supply chain. The two attributes, namely, the quantity and the time, are characterized stochastically.

The model was validated with real data and presented to decision makers in the form of a decision support system with interactive user interface. The system allowed decision makers to run alternative supply chain scenarios by changing the management variables. These scenarios could then be compared in terms of the performance measures. The system was used in the diagnosis of the overall supply chain as well as in streamlining the existing supply chain operations to improve profitability and customer service. 


\subsection{Reengineering the supply chain}

As mentioned in $\S 2$, the supply chain depicted in $\S 4.2$ was managed by function (sales, customer service, forecasting, inventory planning, production planning etc.) and further by market channel (retail, wholesale, industrial, export etc.) on the sales and service side. In such an environment it was not surprising to find the following key observation in the diagnosis phase of an effort to reengineer the order fulfillment process: The process was fragmented with too many hand-offs of both information and physical product, and did not present a consistent, unified interface to the customer. A large part of the redesign was therefore devoted to address this issue.

One candidate design for a new order fulfillment process involved the integration of most of the customer interface and front end planning activities into a new sub-process, called the logistics account management process (LAMP). Specifically, LAMP included taking and delivering customer orders, and was responsible for ensuring that there was adequate stock in the distribution network to fulfill orders. This meant that sales forecasting and finished goods inventory planning would be performed in the same process that dealt with customer orders. Knowledge on customer demands would reside within this process. A new class of jobs, called logistics account managers, had to be created to man the LAMP. The job of logistics account managers was composed of tasks then carried out by several functional departments, and a few new activities which were not performed before. New skills had to be acquired by either training of existing employees or through new hires. A business issue was then how many of such logistics account managers were needed and what customers should be allocated to each team in terms of workload. Would the new process be too expensive (in terms of trade-off between the new supply chain capability and any additional cost)?

In the initial design stage, the principal process flows in the LAMP were captured in a queuing network model using a commercial software package, MPX by Network Dynamics. The objective of the model was to:

(1) establish process feasibility, in terms of staffing levels and customer order response times;

(2) aid the design of customer portfolios, from the view point of work content and load balance of candidate portfolios;

(3) support the development of detailed process design.

A representative customer region was selected for this initial design study. For input to the model, relevant historical demand data were obtained from corporate databases and work flows of existing tasks and estimates of their times were gathered from record files and interviews with appropriate personnel. In establishing process feasibility, quantitative results from the model were provided to the reengineering team and company management to help decide on whether to continue with this design. Some examples are:

(1) minimum total number of logistics account managers required for the customer response desired;

(2) number of logistics account managers by market channel, if we were to retain the 
existing marketing organizational structure (i.e., each channel would have its own team of logistics account managers);

(3) number of logistics account managers required if some tasks were to be assigned to a few specialists (this is a mixture of the current process and the new design).

For strategic reasons the existing marketing structure (by channel) would be maintained, with each channel responsible for its own profit and loss. However, to retain the manufacturing economy of scale (important for a low margin business we were in), the product supply would be shared by the different marketing channels. To maximize risk pooling in the new design, finished goods inventory would not be "tagged" for a particular channel until it was used to fill a customer order, even though the channel planned for it through the LAMP and was independently responsible for their finances and customer service measurements (option 2 immediately above). This created a problem of how to allocate the inventory costs to the different channels. To this end we developed a quantitative inventory measurement model, whose role in the proposed inventory management architecture is shown in figure 5 .

First, the demands for all products were analysed and allocated as a "shared" product or a "private" product to a channel. The criterion for allocation was a specified fraction of sales handled by a channel and a threshold total sales volume. All inventory costs of private products would be carried by the individual channels that owned the products, as these costs were (relatively) too small to be further broken down. For the shared products, the inventory measurement model was applied. The model was based on decomposing the total inventory into logical stockpiles according to the reasons they were there, i.e., the stock drivers. Figure 6 shows the logical stockpiles and their measurement principle. At the end of each accounting period, the measurement model would be executed to allocate

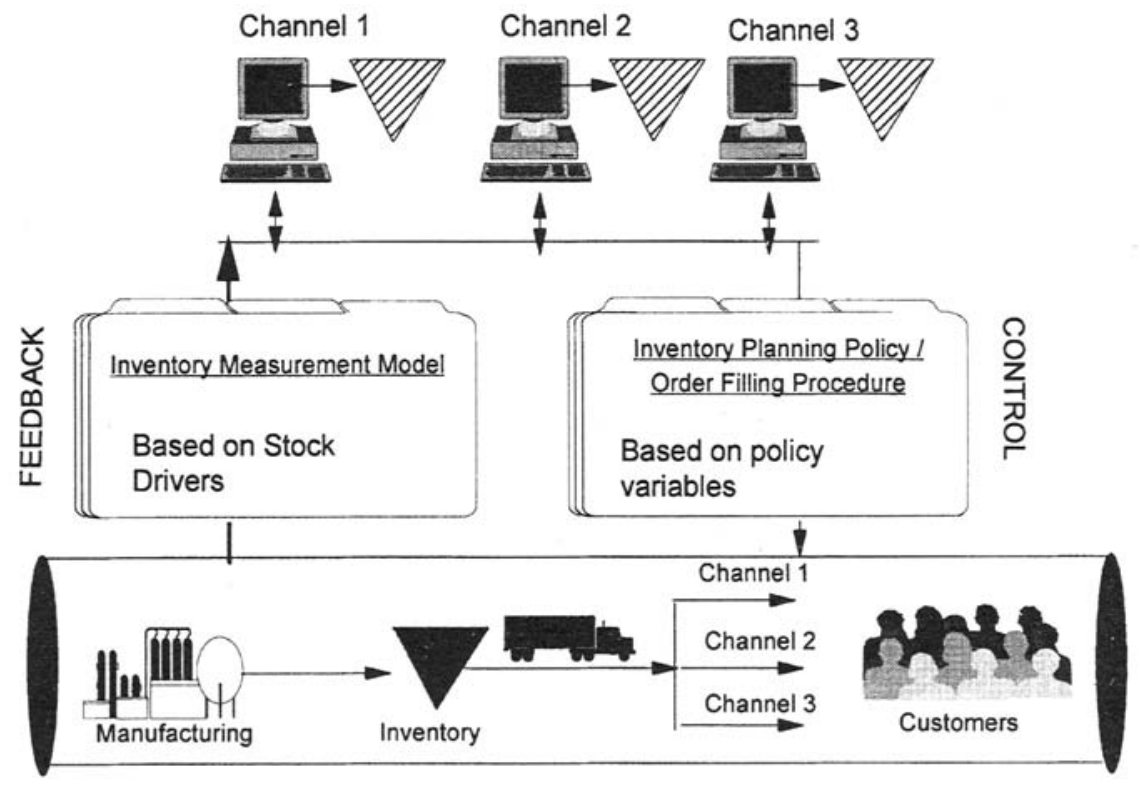

Figure 5. Proposed inventory management architecture. 


\begin{tabular}{|lll|}
\hline Stock driver & Inventory contribution & Measurement principle \\
\hline Production Inflexibility & Supply Stocks & $\begin{array}{l}\text { Attributed to Supply Process } \\
\text { Distribution Pipeline }\end{array}$ \\
Cycle Stocks & $\begin{array}{l}\text { Attributed to channels based } \\
\text { on Sales Volume }\end{array}$ \\
$\begin{array}{l}\text { Supply Lead time Variance } \\
\text { Demand/Forecast Variance } \\
\text { at Product Level }\end{array}$ & $\begin{array}{l}\text { Safety Stocks } \\
\text { Safety Stocks }\end{array}$ & $\begin{array}{l}\text { Attributed to Supply Process } \\
\text { Attributed to channels based } \\
\text { on individual demand/forecast } \\
\text { variance }\end{array}$ \\
Service Levels & Safety Stocks & $\begin{array}{l}\text { Attributed to channels based } \\
\text { on target service levels }\end{array}$ \\
\hline
\end{tabular}

Figure 6. Inventory categorization and measurement basis.

inventory costs to the different channels. An important feature of the model was that it was completely transparent to the goods flow and did not impose any burden on the day-to-day operation of the supply chain. The model could be completely automated with required inputs that were already being measured from the physical system. The model served as a technology enabler of the new process design and, more importantly, provided valuable performance feedback to the management of the different channels.

\subsection{A production supply chain}

A single production plant can also be a supply chain with daunting complexities. We consider a North American display product manufacturer with annual revenues of $\$ 600 \mathrm{M}$. The production process is a hybrid of consumer electronics production (in terms of flexible flow through parallel banks of workstations that operate in tandem with issues of major and minor changeovers) and semiconductor production (in terms of batch processing stages, reentrant flows, and associated yield uncertainties). Complicating this scenario was an uncertain demand, vagaries in the supply of components, and a multi-level bill of assembly shown in figure 7 with each level having its own detailed and complex process route through

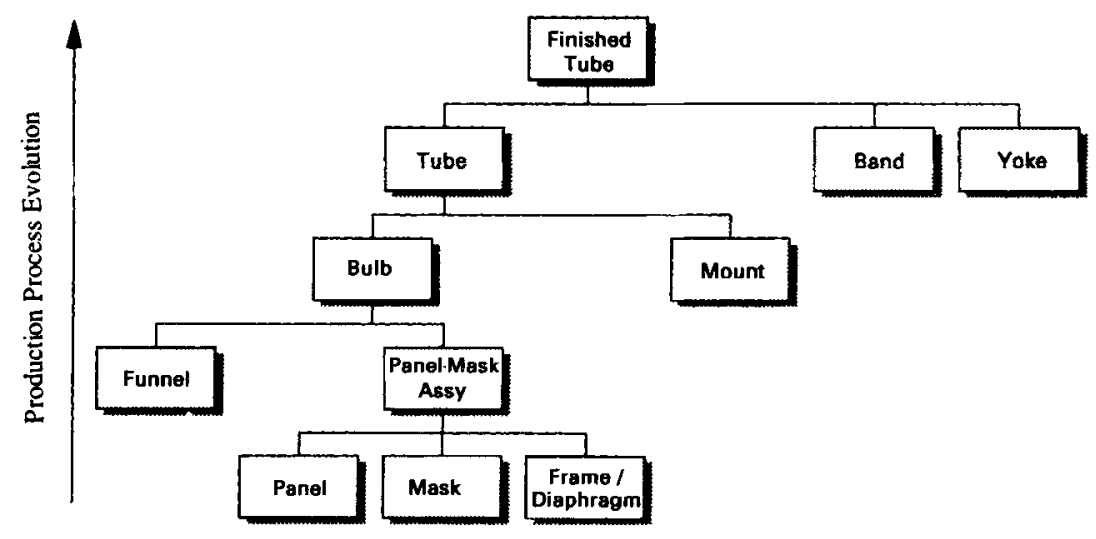

Figure 7. Bill of assembly. 
a network of machine groups. The facility produced three basic families of products. The varying product mix also introduced contentions between these product families for machine capacities.

The facility was plagued with poor delivery performance and having difficulty coping with the process complexity, machine downtimes, varying demand and product mix, and uncertain component supply. In short, the production planning function had an inadequate understanding of the capacity of the plant and was unable to plan effectively. The plant management was interested in reengineering the facility and specifically in evaluating prospective factory layouts. This included outsourcing portions of the overall process and streamlining the process flow in terms of efficient load balancing and process batching. In addition to these structural and manufacturing execution changes, the management was also eager to upgrade the production planning capabilities of the plant in terms of decision support tools.

Typically, capacity calculations that accompany production planning are done using spreadsheets which provide a static snapshot of individual machine capacities. The uncertainty associated with the number of starts, the yield. breakdown of machines, and the complicated process flow are difficult to capture in a static rough-cut capacity calculation. At the other extreme, detailed simulation models can capture the process dynamics but are often too cumbersome to build and too computationally intensive to be of any use as an interactive decision support tool. An efficient and expedient way to model capacity at an aggregate level, that takes into consideration the shopfloor uncertainties and the process dynamics, is using queuing networks (see figure 8).

We used the MPX software to model the process flow based on queuing networks. The arrival and departure process to each workstation, the process time at the workstation, the production yield, and the workstation reliability are stochastically represented. We then solve a number of aggregate dynamic equations that collectively characterize the queuing network. The theoretical basis for the aggregate dynamic models and solution of the queuing network can be seen in Suri et al (1993) and Whitt (1983). Optimization models were also separately built to balance the load across banks of parallel heterogeneous workstations with special flow constraints. A decision support platform was built unifying the MPX and optimization models and providing an interactive user interface for the analyst.

The input for the aggregate capacity model was obtained from various sources. Process flow data were obtained from process layout drawings and based on tours and actual observations of the production process. Process times were estimated based on information provided by production personnel. Process yields were similarly estimated. Machine reliability and changeovers were partly estimated and partly based on historical information.

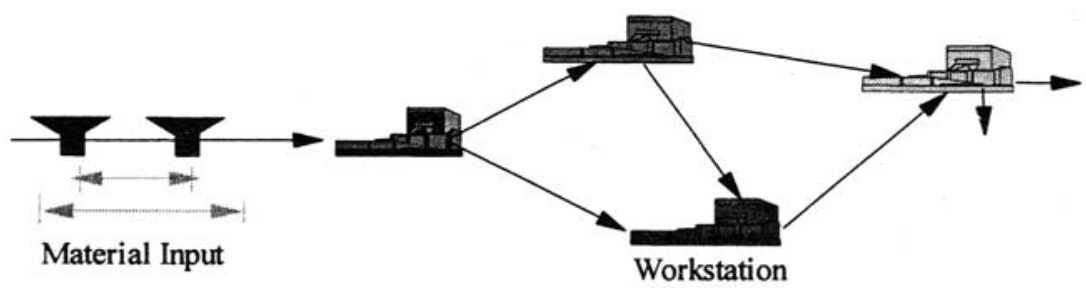

Figure 8. Queuing network representation of process flow. 
Data on material handling devices such as conveyors and monorails that transported goods between workstations were obtained from technical documentation on operating procedures. Historical demand data were also obtained to characterize the product mix and the arrival process to the queuing network.

The MPX model itself served as a practically useful and comprehensive data dictionary for capacity planning and resource allocation. The model served to integrate the fragmentary data that were stored in various media and validate it in the context of capacity and production planning. Further, the data were now in a form that allowed the factory management to easily evaluate prospective factory layouts as part of its reengineering activities. The specific outputs of the capacity model include long-run average performance for individual products in terms of production achieved, yield, flow time, and work-in-progress. The output also includes utilization for machines as well performance for the overall plant. The production planning personnel envisaged the use of this model for forward (given the demand mix how long it takes to produce) and backward (given the horizon what is the feasible production mix) production planning. Additionally, the model can be used in decision support mode for bottleneck, yield, lead time, and work-in-progress inventory analysis of either the overall plant or any segment of the plant.

\section{Concluding remarks}

Quantitative models are very relevant in the diagnosis, redesign, and transition stages of reengineering. They bring concurrency to the diagnosis and redesign stages. Further, the quantitative models provide an objective basis to debate the assumptions and derive alternative designs. Even after the best design is picked the models can be used as part of on-going decision support and planning tools for supply chain management.

Supply chains are of growing interest among businesses as is evident from the rapid growth of supply chain related IT businesses. Following the first-wave of reengineering, organizations have invested heavily in Enterprise Resource Planning (ERP) software such as SAP [URL 12], Baan [URL 13], and BPCS [URL 14] to integrate enterprise-wide transaction data that is contained in heterogeneous databases. At the same time supply chain operational planning software has emerged to offer point solutions such as inventory planning, forecasting, deployment planning and transportation management. In the secondwave of reengineering, organizations are eager to have the various operational planning software inter-operable by integrating them in a flexible manner. Currently no supply chain architecture or supply chain reference model exists that will serve to guide the integration process. At the same time the tactical and strategic planning levels of supply chain management are inadequately served. Quantitative modelling, such as that founded in $\mathrm{OR} / \mathrm{IE}$, can serve a useful purpose to fill this void.

However, traditional OR/IE modelling with sole emphasis on models and data structures will not be adequate (Slats et al 1995). The models will have to be viewed in the larger context of distributed decision support solutions for supply chain management. The models must therefore be designed to support multiple users to support cross-functional decision making. Additionally, the models must be flexibly designed to be reusable and applied to varying decision scenarios. A variety of solution methodologies including heuristics, 
simulation, and optimization will have to be creatively applied to offer high fidelity solutions. Models will also have to be architectured to operate well in distributed environments with data and solvers hosted in different servers over a network. This requires special attention to data communication and processing requirements imposed by the model and the solution strategy.

Quantitative modelling, knowledge of business processes that define real supply chains, and information technology, collectively constitute a powerful and compelling decision technology base for reengineering, integrating, planning, and optimizing supply chains.

\section{References}

\section{Publications}

Aikins J 1993 Business process reengineering: Where do knowledge-based systems fit? IEEE Expert 8: 2

Arntzen B C, Brown G G, Harrison T P, Trafton L L 1995 Global supply chain management at Digital Equipment Corporation. Interfaces 25: 69-93

Ballou R H, Masters J M 1993 Commercial software for locating warehouses and other facilities. J. Business Logistics 14: 71-107

Barrett R 1996 Chasing the BPR Tool Market. Enterprise Reengineering March

Bhaskaran K, Leung Y T 1996 A supply chain performance model. Working Paper. IBM T J Watson Research Center, Yorktown Heights, NY

Blumenfeld D E, Burns L D, Diltz J D, Daganzo C F 1985 Analyzing tradeoffs between transportation, inventory, and production costs on freight networks. Transportation Res. B 19: $361-380$

Blumenfeld D E, Burns L D. Daganzo C. F, Frick M C. Hall R W 1987 Reducing logistics costs at General Motors. Interfaces 17: 26-47

Breitman R L, Lucas J M 1987 PLANETS: A modelling system for business planning. Interfaces 17: 94-106

Childe S J, Maull R S, Bennett J 1994 Frameworks for understanding business process reengineering. Int. J. Oper. Product. Manage. 14: 22-34

Cohen M A, Lee H L 1988 Strategic analysis of integrated production-distribution systems: Model and methods. Oper. Res. 36: 216-288

Cohen M A, Lee H L 1990 The management of integrated production distribution systems. Proc. NSF Design and Manufacturing Systems Conference, Tempe, AZ, pp 259-263

Connors D, An C, Buckley S, Feigin G, Jayraman R, Levas A, Nayak N, Petrakian R, Srinivasan R 1995 Dynamic modelling for business process reengineering. IBM Research Report RC 19944, IBM T J Watson Research Center. Yorktown Heights, NY

Cypress H L 1994 MS/OR imperative: Make second generation of business process improvement mode work. OR/MS Today 21(1): 18-29

Dietrich B, Connors D, Ervolina T, Fasano J P, Lin G, Srinivasan R, Wittrock R, Jayaraman R 1995 Production and procurement planning under resource availability constraints and demand variability. Research Report RC-19948, IBM T.J. Watson Research Center, Yorktown Heights, NY

Feigin G, An C, Connors D. Crawford 1996 Shape up, ship out. OR/MS Today April: 24-30 
Fisher M L, Hammond J H, Obermeyer W R, Raman A 1994 Making supply meet demand in an uncertain world. Harvard Business Review May-June: 83-93

Forrester J W 1958 Industrial dynamics: A major breakthrough for decision makers. Harvard Business Rev. July-August: 37-66

Gangoli N, Jenkins R T 1988 Distribution system design with SAS/OR and the matrix generator. Proceedings of the 13th Annual SAS Users Group International Conference, Orlando, FL, pp 194-198

Geoffrion A M 1976 Better distribution planning with computer models. Harvard Business Rev. July-August: 92-99

Geoffrion A M, Graves G W 1974 Multi-commodity distribution system design by Benders decomposition. Manage. Sci. 20: 50-67

Hammer M, Champy J 1993 Reengineering the corporation (New York, NY: Harper Business)

Hansen G 1994 A complex process: The case for automated assistance in business process reengineering. OR/MS Today August: $34-41$

Hanssmann F 1959 Optimal inventory location and control in production and distribution network. Oper. Res. 7: 483-498

Harrington H J 1992 Business process improvement (New York, NY: McGraw-Hill)

Hax A C, Majluf N, Pendrock M 1980 Diagnostic analysis of a production and distribution system. Manage. Sci. 26: 871-889

Lee H L 1993 Design for supply chain management: Methods and examples. Perspectives in operations management: Essays in Honor of Elwood S Buffa (ed.) R Sarin (Boston, MA: Kluwer Academic) pp 45-65

Lee H L 1996 Effective inventory and service management through product and process redesign. Oper. Res. 44: 151-159

Lee H L, Billington C 1992 Managing supply chain inventory: Pitfalls and opportunities. Sloan Manage. Rev. Spring: $65-73$

Lee H L, Billington C 1995 The evolution of supply-chain-management models and practice at Hewlett-Packard. Interfaces 25: 42-63

Leung Y T 1995 Commercial software for distribution network optimization: A survey of current products. White Paper, IBM T.J. Watson Research Center, Yorktown Heights, NY

Malhotra R, Jayaraman S 1992 An integrated framework for enterprise modeling. J. Manuf. Syst. 11: 426-441

Mather H 1992 Design for logistics (DFL) - The next challenge for designers. Product. Inventory Manage. J. (First Quarter): 7-10

Mercer A, Tao X 1996 Alternative inventory and distribution policies of a food manufacturer. $J$. Oper. Res. Soc. 47: 755-765

Pooley J 1994 Integrated production and distribution facility planning at Ault Foods. Interfaces 24: 113-121

Pyke D F, Cohen M A 1990 Effects of flexibility through set-up time reduction and expediting on integrated production-distribution systems. IEEE Trans. Robotics Autom. 6: 609-620

Rovira M 1996 Private communication. IBM T J Watson Research Center, Yorktown Heights, NY

Sharda R 1995 Linear programming solver software for personal computers: 1995 report. $O R / M S$ Today 22(5): 49-51

Slats P A, Bhola B, Evers J J M, Dijkhuizen G 1995 Logistic chain modelling. Eur. J. Oper. Res. 87: $1-20$

Stalk G, Evans P, Shulman L E 1992 Competing on capabilities: The new rules of corporate strategy. Harvard Business Rev. March-April: 57-69 
Suri R, Sanders J L, Kamath M 1993 Performance evaluation of production networks. Handbooks in Operations Research and Management Science (eds) S C Graves, A H G Rinnooy Kan, P H Zipkins (Amsterdam: North Holland) 4: 199-286

Whitt W 1983 The queueing network analyzer. Bell. Syst. Tech. J. 62: 2779-2815

World-Wide Web References

[URL 1] http://nemo.ncsl.nist.gov/ standsp/stand.html: IDEF Standards

[URL 2] http://www.wizdom.com/bpr/cpr.html; WizdomWorks Home Page.

[URL 3] http://www.ctt.fi/tte/staff/ojp/workflow.html; Workflow related internet resources.

[URL 4] http://www.software.ibm.com/ad/promodel/bmtn0mst.htm; IBM Business Process Modeler.

[URL 5] http://www.cayennesoft.com/products/erwinteam.htm; IDEF with CASE functionality.

[URL 6] http://www.research.ibm.com/sas.html; BPMAT - IBM Software Application and Services.

[URL 7] http://www.sm.com/arena.htm; ARENA by Systems Modeling Corporation.

[URL8] http://www.imaginethatinc.com/home.html; Extend Simulation Software Home Page.

[URL 9] http://duticai.twi.tudelft.nl/lists/bpr-l/faq/tools.html; Archive of tools for BPR.

[URL 10] http://www.caps.com; CAPS Logistics Toolkit home page.

[URL 11] http://www.sas.com; SAS Institute.

[URL 12] http://www.sap.com; SAP AG Inc.

[URL 13] http://www.baan.com; The Baan Company.

[URL 14] http://www.ssax.com; System Software Associates Inc. 